\title{
ВЛИЯНИЕ СПЛОШНЫХ РУБОК НА ЛЕСОРАСТИТЕЛЬНЫЕ СВОЙСТВА ПОЧВ БРАТСКОГО РАЙОНА ИРКУТСКОЙ ОБЛАСТИ
}

\author{
О. Г. Лопатовская ${ }^{1}$, Е. Н. Максимова', В. В. Попов ${ }^{2}$, К. С. Соловьева ${ }^{1}$ \\ 1 Иркутский государственный университет, г. Иркутск, Российская Федерация \\ 2 Байкальский государственный университет, г. Иркутск, Российская Федерация
}

\author{
Информация о статье \\ Дата поступления \\ 10 января 2018 г. \\ Дата принятия к печати \\ 28 февраля 2018 г. \\ Дата онлайн-размещения \\ 30 марта 2018 г.

\section{Ключевые слова} \\ Вырубки; лесорастительные \\ свойства; почва; физические \\ и химические свойства

\section{Финансирование} \\ Работа выполнена \\ при фринансовой поддержке \\ фрилиала ОАО «Группа «Илим» \\ в Братском районе
}

\begin{abstract}
Аннотация
Приводятся результаты исследований по оценке влияния сплошных рубок на лесорастительные свойства почв Братского района Иркутской области. На вырубках разных годов динамика изменения физических и химических свойств почв незначительна, в то время как почвы контрольного участка по свойствам отличаются от нарушенных. Почва после сведения леса может считаться антропогенно-преобразованной в верхних горизонтах, внутрипочвенные горизонты изменению не подвергались. В целом нарушение почвенного покрова происходит в основном в верхних горизонтах. Выявлено, что сплошные рубки изменяют лесорастительные свойства почв. При этом происходит обогащение верхнего горизонта почвы доступными фрормами элементов минерального питания растений, снижается кислотность почвы, уменьшается содержание органического вещества, снижается влажность, возрастает доля травянистых растений, увеличивается их видовой состав, повышается продуктивность травяного яруса. Почвы вырубок без почвенно-растительного покрова подвержены эрозионным процессам - дефляции, линейной эрозии (образование оврагов), плоскостному смыву. Следовательно, целесообразны мероприятия по лесовосстановлению.
\end{abstract}

\section{THE INFLUENCE OF CLEARCUT LOGGING ON THE FOREST GROWTH PROPERTIES OF SOILS OF BRATSK DISTRICT OF IRKUTSK OBLAST}

\author{
Olga G. Lopatovskaya ${ }^{1}$, Evgeniya N. Maksimova', Viktor V. Popov², \\ Kseniya S. Solovyova ${ }^{1}$ \\ ${ }^{1}$ Irkutsk State University, Irkutsk, the Russian Federation \\ ${ }^{2}$ Baikal State University, Irkutsk, the Russian Federation
}

Article info

Received

January 10, 2018

Accepted

February 28, 2018

Available online March 30, 2018

\section{Keywords}

Wood felling; forest growth properties; soil; physical and chemical properties

\begin{abstract}
The article is dedicated to the results of studies on the evaluation of the effect of clearcut logging on the forest growth properties of soils in the Bratsk District of Irkutsk Oblast. We found that the dynamics of changes in the physical and chemical properties of soils on the logged areas is negligible, while the soils of the control plot differ in properties from disturbed soils. The soil after deforestation can be considered anthropogenically transformed in the upper horizons; the intrasoil horizons have not been changed. In general, the disturbance of the soil cover occurs mainly in the upper horizons. We found that clearcut logging changes the forest growing characteristics of soils. In this case, the upper soil horizon is enriched with accessible forms of elements of mineral nutrition of plants; the acidity of soil, the content of organic matter and the moisture content decrease; the proportion of herbaceous plants and their species composition increase; the productivity of the herbaceous layer grows. Soils at
\end{abstract}


Acknowledgements

This research has been done with the financial support of the branch of the Open JSC

«llim Group» in the Bratsk District logged areas that have no vegetation and topsoil are subject to erosion processes - deflation, linear erosion (formation of ravines), sheet flood erosion. Consequently, measures for reforestation are advisable.
Введение. Влияние растительности как ведущего фактора в почвообразовании исключительно велико [1]. Оно проявляется в обмене веществом и энергией, в водном и тепловом режимах почв. Характер растительности нередко определяет направление почвообразования.

Одним из возможных последствий сплошных рубок выступает заболачивание почв в результате изменения гидрологического режима. Это обусловлено увеличением суммарного количества осадков, поступающих на поверхность почвы, и уменьшением влаги, испаряемой в результате транспирации растений. Повышение содержания влаги ухудшает аэрацию почвы. Чем беднее средне- и сильноувлажненные почвы, тем вероятнее их заболачивание. Огромна в развитии заболачивания роль растительности, развивающейся на вырубках на первых стадиях сукцессии. В условиях влажности климата после вырубки древостоя формируется сплошной моховой покров. Обладая значительной влагоемкостью, мхи снижают газообмен между атмосферой приземного слоя и почвой, ухудшают ее аэрацию, что создает условия для увеличения влажности верхнего слоя почвы, способствует повышению уровня верховодки, прогрессирующему оглеению [2; 3].

При сплошных рубках создаются условия для минерализации подстилки и других растительных остатков, происходит обогащение верхнего горизонта почвы доступными фрормами элементов минерального питания растений, особенно азота, нередко снижается кислотность почвы [3]. Возрастает доля травянистых растений, увеличивается их видовой состав, повышается продуктивность травяного яруса. От типа почв, времени, прошедшего с момента рубки, степени развития дернового процесса под вторичными травянистыми ценозами и степени проявления эрозионных процессов зависит содержание гумуса ${ }^{1}[4]$.

С целью выявления генезиса и развития почвенного покрова, для предварительной

${ }^{1}$ ОСТ 56-81-84. Полевые исследования почвы. Порядок и способы проведения работ, основные требования к результатам : утв. приказом Гослесхоза СССР от 12 окт. 1984 г. № 140. URL: http://www.gosthelp.ru/ text/OST568184Polevyeissledova.html. оценки потенциальных лесорастительных возможностей местоположения, условий лесовозобновления и лесовосстановления, влияния лесохозяйственных и рекреационных воздействий на почву, выявления ее физических и химических свойств были проведены исследования по оценке влияния сплошных рубок на лесорастительные свойства почв на площадке вырубки леса «Тарма» в Братском районе Иркутской области.

Объекты и методы исследования. Исследования проводились в Братском районе, расположенном на северо-западе Иркутской области. Растительность района находится в экстремальных условиях по температурам, необходимым для вегетационного периода. Продолжительность безморозного периода колеблется в пределах от 73 до 127 дней. Средняя продолжительность периода с устойчивым снежным покровом - 180 дней.

Для характеристики условий почвообразования было сделано описание ландшафта, определено расположение и границы объекта на местности, сделана геоботаническая, лесоводственная характеристика.

Полевые исследования включали в себя: заложение почвенного разреза до появления почвообразующей породы и почвенную прикопку (для наблюдения строения почвы); полнопрофильное описание почвы с указанием основных морфологических признаков (цвет, грансостав, структура, новообразование и включения, влажность, пронизанность корневой системой, вскипание, характер перехода в нижние горизонты, граница перехода); характеристику почвенного профриля с выделением генетических горизонтов; отбор почвенных образцов. Почвенный профиль фотографировался.

Почвенные разрезы были заложены на участках бывших лесных земель. Всего было выделено пять площадок - контрольная и четыре площадки вырубок различных лет (1996, 2007, 2010 и 2016 гг.).

Отбор почвенных образцов проводился согласно общепринятым В почвоведении методам [5-9]. Почвенные образцы отбирались из каждого генетического горизонта массой 800-1 000 ги помещались в пластиковые пакеты. Одновременно подписывались этикетки, на которых указывалось место заложения разреза, глубина отбора пробы, 
название генетического горизонта, дата отбора пробы. Почвенные этикетки также помещались в пластиковые пакеты. Одновременно почвам присваивалось название согласно классификации почв [10; 11$]$.

Контрольная площадка (площадью 20 га) расположена в 10-м квартале в выделах 2 и 3, непосредственно примыкающих к вырубкам. Согласно таксационному описанию, насаждения в выделе 2 представлены 5Б4ОС1С, высота 16-21 м, полнота 7, возраст около 80 лет, подрост С2К4П, в выделе 3 насаждения 6С2Л2Б, возраст 110 лет, высота 19-2 м, полнота 6, подрост 4 6С4Б (25), высота около 3 м, подлесок густой.

Вырубка 1996 г. находится в 9-м квартале в выделах 37 и 41. Площадь вырубки около 25 га. Представлена смешанным лесом с отдельными старыми деревьями. Граничит с одной стороны с вырубкой 2011 г., с другой стороны (выдел 41) - со старым, не вырубленным лесом.

Вырубка 2007 г. расположена в 10-м квартале в выделе 7 (площадью 40 га), представлена в основном молодыми березами и осинами, проведены работы по посадке саженцев сосны.

Вырубка 2011 г. находится в 10-м квартале в выделе 8 (площадью 31 га), представлена в основном молодыми березами и осинами, проведены работы по посадке саженцев сосны.

Вырубка 2016 г. расположена в 19-м квартале в выделах 2 и 6 (площадью 37 га). Сохранились одиночные деревья и куртины сосны, лиственницы и березы, оставлена полоса леса шириной около 30 м.

В районе исследования опад темнохвойных и лиственничных древесных пород обладает меньшей зольностью по сравнению с тем, что формируется на многолетних вырубках. Кроме того, он предопределяет недоусредненность продуктов гумификации, их кислый характер при господстве нисходящего тока - образование аккумулятивно-илювиальных гумусовых горизонтов (контроль). Под покровом травянистых лесов (вырубки 1996, 2007, 2010 гг.) образуются аккумулятивные гумусовые горизонты, менее кислая реакция среды.

На территории распространения восстановительной серии моховых темнохвойных лесов чаще, чем где-либо, наблюдается несоответствие строения и свойств почв характеру современного растительного покрова.

Основным типом почв, которые были описаны в районе, являются дерново-карбонатные почвы [10], которые в классифи- кации 2004 г. [11] названы бурозёмами. Под гумусовым горизонтом залегает структурно-метаморфический горизонт BM бурых или охристых тонов окраски, сформированный за счет ожелезнения на месте. Гранулометрический состав слабо диффференцирован по профрилю. Структура комковатая или ореховато-комковатая с вариабельностью структурных отдельностей. В строении почвенного профиля выделяются горизонты AY-BM-C.

Дерново-карбонатные почвы орографически приурочены ко всем положительным элементам рельефра. В их распределении наблюдается четко выраженная дифференциация: с высотой дерново-карбонатные типичные почвы сменяются выщелоченными, затем оподзоленными. В этом же направлении ухудшаются агропроизводственные свойства почв, так как уменьшается мощность профиля и увеличивается каменистость.

Дерново-карбонатные почвы приурочены к территориям, сложенным известняками, доломитами (рендзины) и красноцветными карбонатно-силикатными породами (парарендзины). Почвы на карбонатно-силикатных породах унаследовали от них красновато-коричневую окраску, отличаются устойчивой структурой и противостоят скорому выпахиванию и истощению, обладают высоким плодородием. Почвы, развитые на карбонатных породах, характеризуются серой, темно-серой окраской гумусового горизонта и бурой, буровато-желтой окраской нижележащих горизонтов. Богатство пород карбонатами, а также слабый вынос продуктов выветривания и почвообразования вследствие малого количества осадков и позднего оттаивания сезонной мерзлоты препятствуют развитию подзолистого процесса.

Все дерново-карбонатные почвы имеют в своем профиле углесоли, которые в почвенной толще чаще распределяются дифффузно. Иногда карбонаты представлены белоглазкой или прожилками мучнистой извести. Значительное содержание карбонатов в породе препятствует развитию процессов подзолообразования в дерново-карбонатных почвах. Однако с течением времени под влиянием совокупного воздействия климатического и биологического фракторов углесоли постепенно выносятся из верхних горизонтов почв, и фрормируются выщелоченные почвы. Гумусовый горизонт имеет различную мощность (15-40 см, иногда больше), красновато-бурую, темно-серую или серовато-бурую 
окраску. Структура горизонта комковатая или комковато-зернисто-порошистая. Внутрипочвенный иллювиальный горизонт уплотнен, оглинен, более ярко окрашен, чем нижний, в охристые тона.

Дерново-карбонатные оподзоленные почвы встречаются преимущественно под лесами. Формируются на породах, содержащих в исходном состоянии малое количество углесолей, или на сильновыщелоченных карбонатных породах.

Результаты исследований. В естественном состоянии морфологический профиль почв четко диффреренцирован на горизонты, характеризуется наличием дернового горизонта А небольшой мощности (5-15 см, редко больше). Под ним залегает белесоватый рыхлый оподзоленный горизонт часто более легкого гранулометрического состава (5-15 см). Иллювиальный горизонт сильно уплотнен, яснозернистой структуры. Материнская порода иногда выщелочена от углесолей, чаще содержит их и вскипает от соляной кислоты.

Структура верхних горизонтов почв комковато-порошистая, пыли на поверхности почвы очень мало, но иногда давность освоения и эрозия могут привести к увеличению содержания пыли в пахотном слое. В таких почвах преобладают структурные элементы крупнее 10 мм и мельче 0,25 мм. Тем временем достаточно точно установлено, что лучшими свойствами обладают агрегаты размером от 0,5 до 2-3 мм. Результаты мокрого просеивания указывают на малую прочность агрегатов.

По данным микроагрегатного анализа, преобладают частицы размером 0,250,05 мм. Верхний горизонт характеризуется благоприятным соотношением между глыбистой (>10 мм), комковатой (10-1 мм) и распыленной (<1 мм) частями в сухом состоянии. Глыбистость и пылеватость незначительны.

По запасам питательных веществ лучшими являются многогумусные виды. Они залегают по рельефу ниже, чем мало-, среднегумусные почвы, и отличаются темно-серой окраской гумусового горизонта; содержат большое количество гумуса (более 5 \%, иногда до $12 \%)$ и азота. Пониженное содержание гумуса в поверхностных слоях некоторых почв может быть обусловлено эрозией и вспашкой комплексных почв.

По гранулометрическому составу почвы от легкосуглинистых до глинистых. Преобладают иловатая и крупнопылеватая фракции, иногда мелкопесчаная. У таких почв иногда отмечается опесчаненность поверхностного слоя как проявление эрозионных процессов. Характерно накопление железа и алюминия в иллювиальном горизонте и относительное обогащение кремнеземом горизонтов гумусового и элювиального.

Порозность в данных почвах достаточно высокая, но по профилю она сильно изменяется в сторону уменьшения. Разрыхление гумусового горизонта объясняется высоким содержанием органического вещества. Вниз по профилю почва уплотняется.

Почвы имеют слабокислую и близкую к нейтральной реакцию почвенного раствора. Количество поглощенных оснований в оподзоленном горизонте уменьшается, а затем снова возрастает. Гидролитическая кислотность велика в верхнем горизонте, с глубиной она резко уменьшается. Степень насыщенности почв основаниями достигает 80-90\%. Содержание гумуса в перегнойном горизонте колеблется в значительных пределах (от 0,1 до 11 \%). Запасы органического вещества невелики из-за малой мощности гумусового горизонта. Состав гумуса фульватно-гуматный.

В поверхностном слое лесных почв наблюдается повышенное содержание калия, что можно объяснить его биологической аккумуляцией. Фосфатами почвы низкообеспечены.

Наиболее кислый $\mathrm{pH}$ отмечен в контрольной точке. Это связано с тем, что почвы фрормируются в условиях постоянного воздействия «кислого» опада хвойных пород деревьев. Некоторое увеличение $\mathrm{pH}$ в точке, соответствующей 2007 г., возможно за счет того, что почвообразующие породы содержат незначительное количество карбонатов кальция. В почве, которая соответствует 1996 г., отмечается некоторое увеличение рН в сторону нейтральной среды.

В целом анализ почв по наличию актуальной кислотности показал, что все почвы имеют слабокислый и кислый рН (рис. 1).

Поскольку почвы относятся к лесным, содержание в них легко растворимых в воде компонентов, которые показывают общую минерализацию, невысокое. Наибольшее количество веществ находится в точке, соответствующей контролю. Это связано с наличием легкорастворимого органического вещества. Это коррелирует с результатами определения гумуса в этой почве. Во всех других случаях почвы не имеют ни засоления, ни содержания других растворимых в воде веществ (рис. 2). 

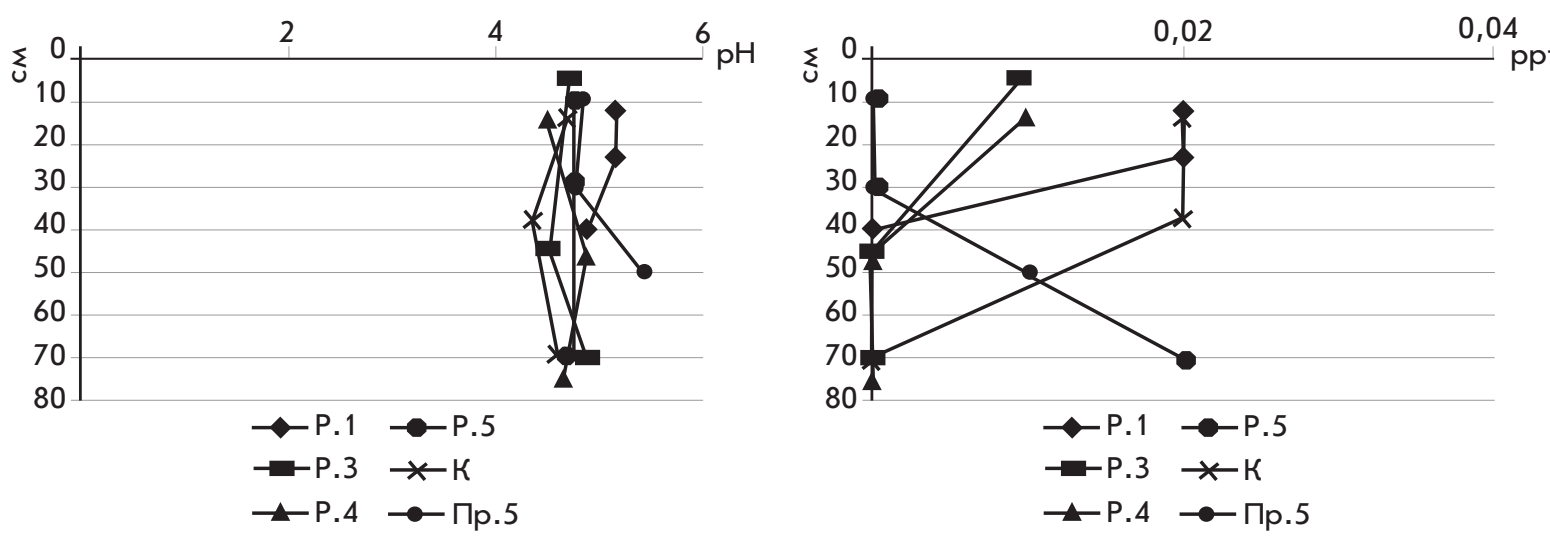

Рис. 1. Изменение рН почвенной суспензии и концентрации растворимых веществ

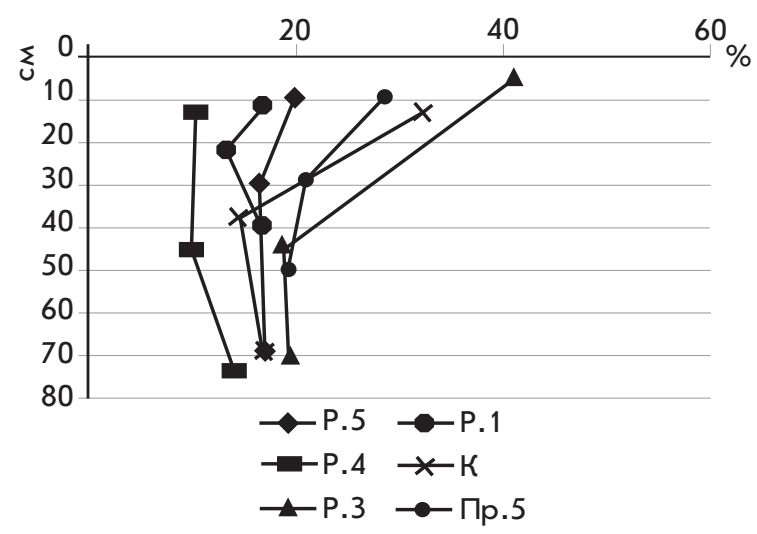

a

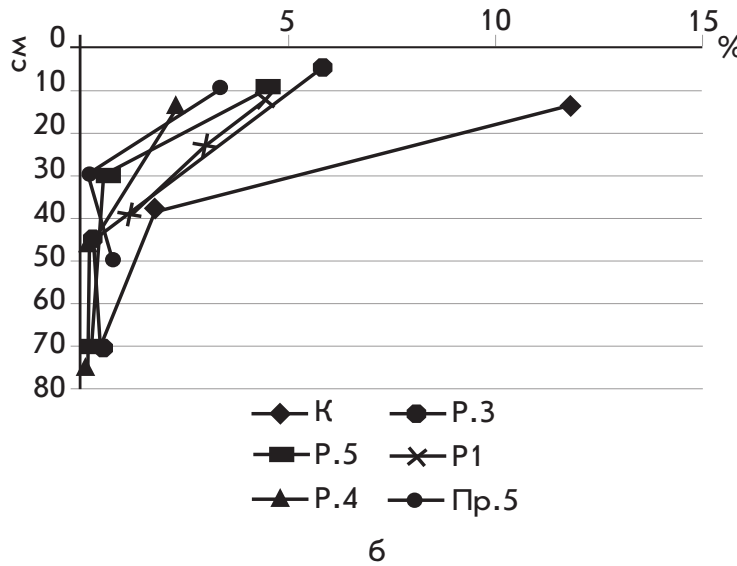

6

Рис. 2. Изменение естественной влажности почв (а) и содержания гумуса (б)

Анализы показали, что в точке, соответствующей контролю, наибольшая влажность сохраняется в верхних горизонтах до горизонта В и затем снова увеличивается, так как растительность способствует сохранению влаги, препятствует испарению воды с поверхности почвы. Кроме того, высока влажность в почвах, соответствующих вырубке 2016 г. Наверх были вынесены внутрипочвенные глинистые горизонты. На месте редколесья, соответствующего площадкам вырубок 1996, 2007 и 2010 гг., влажность почв меньше (см. рис. 2). Из-за незначительного проективного покрытия влажность почв низкая, поскольку происходит испарение влаги с поверхности почвы, которое, в свою очередь, связано с небольшим проективным покрытием данной территории.

В почве, соответствующей контролю, наибольшее содержание гумуса. Высокие концентрации органического вещества в верхней части связаны с наличием лесной подстилки, представленной мхами и лишайниками. В точке, соответствующей 2016 г. , также высоко содержание органического вещества. При полевом обследовании было выявлено, что на поверхности почвы остались высушенные остатки мхов.

Органическое вещество - величина непостоянная. При минерализации содержа- ние гумуса в почве уменьшается, поэтому в почвах, соответствующих вырубкам 2007 и 2010 гг., содержание гумуса минимальное. Однако в почвах, соответствующих вырубке 1996 г., отмечено повышение содержания органического вещества за счет формирования дернового горизонта.

Полевое определение почв показало, что наименьшими температурами в летний период обладают почвы, соответствующие участку «контроль», затем почвы 2010 г. По возрастанию температур находятся почвы 1996, 2016, 2007 гг. (рис. 3).

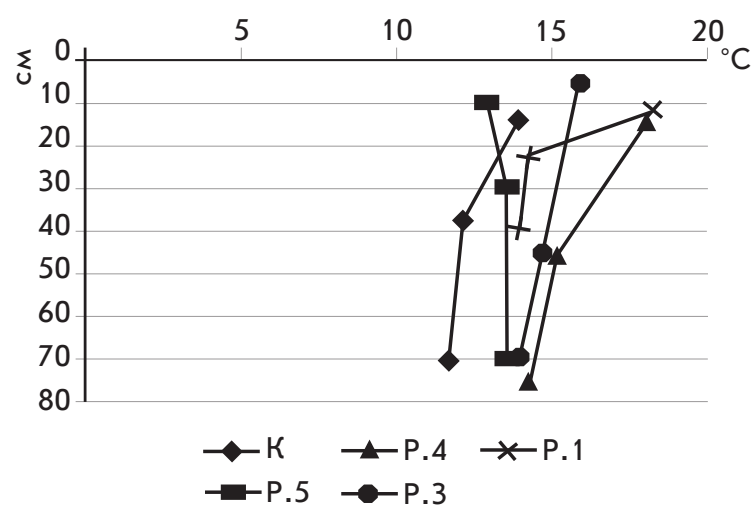

Рис. 3. Изменение температур 
В процессе вырубки леса происходит переворачивание верхних гумусовых горизонтов, на поверхность выходят внутрипочвенные, которые могут быть иными по сравнению с контролем по грансоставу (наличие песчаных или глинистых частиц). На контрольном участке влагоемкость в гумусовом горизонте ниже, чем в горизонте иллювиальном. Это связано с тем, что верхние горизонты более рыхлые, а внутрипочвенные содержат больше глинистых частиц и по грансоставу являются средне- и тяжелосуглинистыми. $\mathrm{Ha}$ рис. 4 показано, что влагоемкость контрольного и других участков различна. Структура почвы наиболее ценная в контрольном разрезе. В других точках отбора проб почва среднеструктурирована.
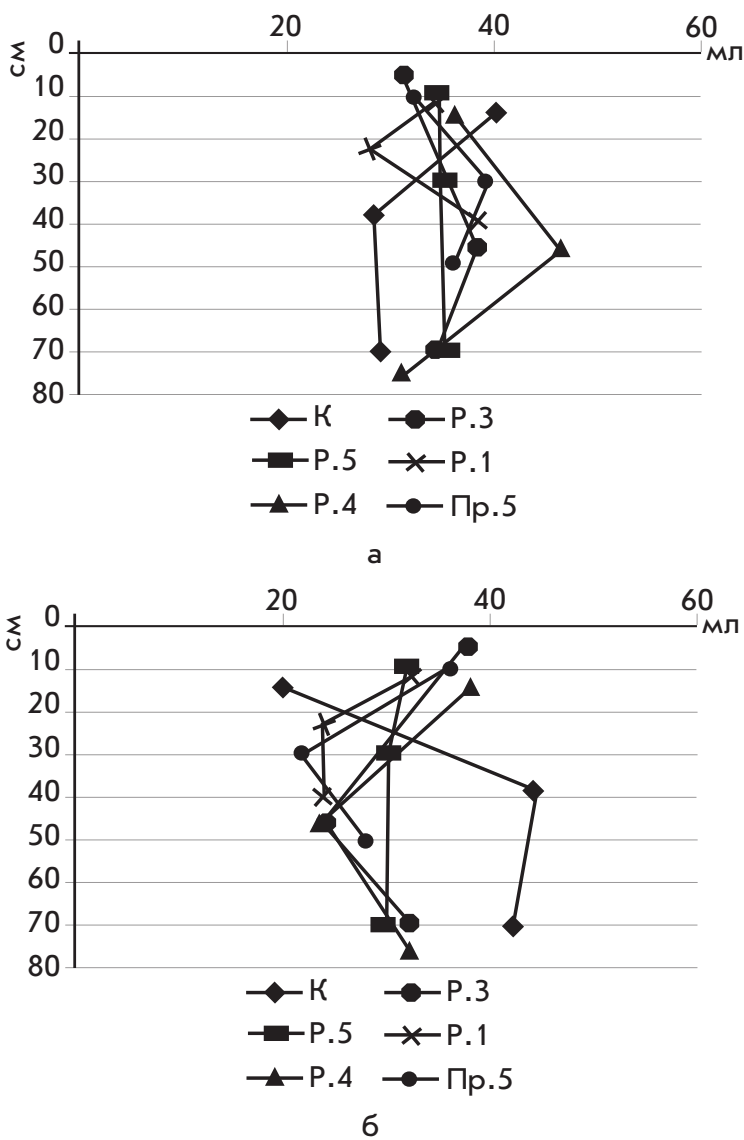

Рис. 4. Водоотдача (а) и влагоемкость (6) почв

После вырубок поверхность почвы зарастает медленно. Это связано с тем, что на поверхность выносится не плодородный горизонт, который содержит гумус в десятых долях процента, но обогащен глинистыми частицами. Это приводит к активности эрозионных процессов: линейная эрозия, плоскостной смыв и дефрляция. Поэтому в результате сведения растительности происходят процессы, связанные с деградацией почв, изменение водного и воздушного режимов.

\section{Выводы:}

1. Наиболее кислый $\mathrm{pH}$ в контрольной точке, в других происходит подщелачивание почв за счет аккумуляции элементов из нижних горизонтов на поверхность внутрипочвенных горизонтов. Наибольшая концентрация растворимых в воде веществ в контрольной точке за счет растворимых органических веществ. Наибольшее количество органического вещества в почвах, соответствующих контролю, за счет мощного гумусового горизонта и наличия подстилки.

2. Влажность почвы наибольшая в контрольной точке, в других разрезах влажность незначительно изменяется. Наименьшая влажность в разрезе на месте редколесья, соответствующем вырубке 2007 г., из-за незначительного проективного покрытия. В ходе вырубок происходит вынос на поверхность глинистых частиц, которые обладают большей водоудерживающей способностью. Меньшими температурами в летний период обладают почвы, соответствующие участку «контроль» (в лесу летом прохладнее, чем на открытом участке), на других площадках температуры почв по всему профилю незначительно выше. Структура почвы изменяется от хорошей до средней, в контрольном разрезе - хорошая.

3. На вырубках разных годов динамика изменения физических и химических свойств незначительна, в то время как почвы контрольного участка по свойствам отличаются от нарушенных. Почва после сведения леса может считаться антропогенно-преобразованной в верхних горизонтах, внутрипочвенные горизонты изменению не подвергались. В целом нарушение почвенного покрова происходит в основном в верхних горизонтах.

4. Почвы вырубок без почвенно-растительного покрова подвержены эрозионным процессам: дефляции, линейной эрозии (образование оврагов), плоскостному смыву, поэтому целесообразны мероприятия по лесовосстановлению.

\section{СПИСОК ИСПОЛЬЗОВАННОЙ ЛИТЕРАТУРЫ}

1. Базовые шкалы свойств морфологических элементов почв : метод. руководство по описанию почв в поле / сост. Э. А. Корнблюм [и др.]. - М. : Почв. ин-т им. В. В. Докучаева, 1982. - 57 с.

2. Классификация и диагностика почв СССР / В. В. Егоров [и др.]. - М. : Колос, 1977. - 221 с.

3. Классификация почв России / сост. Л. Л. Шишов [и др.]. - Смоленск : Ойкумена, 2004. - 342 с. 
4. Поляков А. И. Изменение горно-лесных экосистем Северного Кавказа вследствие вырубки леса / А. И. Поляков / / Известия вузов. Северо-Кавказский регион. Естественные науки. - 2010. - № 4. - С. $113-114$.

5. Поляков А. И. Влияние вырубки леса на биологические свойства горных почв Западного Кавказа : автореф. дис. ... канд. биол. наук : 03.02.08 / А. И. Поляков. - Ростов н/Д., 2011. - 24 с.

6. Почвенно-географические и ландшафтно-геохимические исследования в зоне БАМ / сост. В. А. Снытко. Новосибирск : Наука, 1980. - 183 с.

7. Работнов Т. А. Фитоценология : учеб. пособие / Т. А. Работнов. - 2-е изд. - М. : Изд-во МГУ, 1983. - 296 с.

8. Ремезов Н. П. Лесное почвоведение / Н. П. Ремезов, П. С. Погребняк. - М. : Лесная пром-сть, 1965.

9. Розанов Б. Г. Морфология почв / Б. Г. Розанов. - М. : Изд-во МГУ, 1983. - 320 с.

10. Розанов Б. Г. Морфология почв : учебник / Б. Г. Розанов. - М. : Акад. проект, $2004 .-432$ с.

11. Самофралова И. А. Полевая учебная практика по географии почв с основами картографии : учеб. пособие / И. А. Самофалова, В. П. Дьяков. - Пермь : Изд-во Перм. гос. с.-х. академии, 2010. - 111 с.

\section{REFERENCES}

1. Kornblyum E. A., Mikhailov I. S., Nogina N. A., Targulyan V. O. Bazovye shkaly svoistv morfologicheskikh elementov pochv [Basic Scales of Propreties of Morphological Elements of Soils]. Moscow, V. V. Dokuchaev Soil Science Institute Publ., 1982. 57 p.

2. Egorov V. V., Fridland V. M., Ivanova E. N., Rozov N. N. Klassifikatsiya i diagnostika pochv SSSR [Classification and Diagnostics of the USSR's Soils]. Moscow, Kolos Publ., 1977. 221 p.

3. Shishov L. L., Tonkonogov V. D., Lebedeva I. I., Gerasimova M. I. (eds.). Klassifikatsiya pochv Rossii [Classification of Russia's Soils]. Smolensk, Oikumena Publ., 2004. 342 p.

4. Polyakov A. I. Change in Mountain-Forest Ecosystems of the North Caucasus Due to Deforestation. Izvestiya vuzov. Severo-Kavkazskii region. Estestvennye nauki = University news North-Caucasian region. Natural sciences series, 2010, no. 4, pp. 113-114. (In Russian).

5. Polyakov A. I. Vliyanie vyrubki lesa na biologicheskie svoistva gornykh pochv Zapadnogo Kavkaza. Avtoref. Kand. Diss. [Influence of Deforestation on Biological Properties of Mountain Soils of North Caucasus. Cand. Diss. Thesis]. Rostov-on-Don, 2011. 24 p.

6. Snytko V. A. (ed.). Pochvenno-geograficheskie i landshaftno-geokhimicheskie issledovaniya v zone BAM [Soil-Geographic and Landscape-Geochemical Studies in the Baikal-Amur Mainline Zone]. Novosibirsk, Nauka Publ., 1980. 183 p.

7. Rabotnov T. A. Fitotsenologiya [Phytosociology]. $2^{\text {nd }}$ ed. Lomonosov Moscow State University Publ., 1983. 296 p.

8. Remezov N. P., Pogrebnyak P. S. Lesnoe pochvovedenie [Forest Soil Science]. Moscow, Lesnaya promyshlennost' Publ., 1965. 323 p.

9. Rozanov B. G. Morfologiya pochv [Soil Morphology]. Lomonosov Moscow State University Publ., 1983. 320 p.

10. Rozanov B. G. Morfologiya pochv [Soil Morphology]. Moscow, Akademicheskii proekt Publ., 2004. 432 p.

11. Samofalova I. A., Dyakov V. P. Polevaya uchebnaya praktika po geografii pochv s osnovami kartografii [Field Training in Geography of Soils with the Basics of Cartography]. Perm State Agricultural Academy Publ., 2010. 111 p.

\section{Информация об авторах}

Лопатовская Ольга Геннадьевна - кандидат биологических наук, доцент, кафедра почвоведения и оценки земельных ресурсов, Иркутский государственный университет, 664011, г. Иркутск, ул. Сухэ-Батора, 5, e-mail: lopatovs@gmail.com.

Максимова Евгения Николаевна - кандидат биологических наук, доцент, кафедра естественнонаучных дисциплин, Иркутский государственный университет, 664011, г. Иркутск, ул. Сухэ-Батора, 9, e-mail: evgen_max@list.ru.

Попов Виктор Васильевич - кандидат биологических наук, директор Института природопользования и сохранения биоразнообразия, Байкальский государственный университет, 664003, г. Иркутск, ул. Ленина, 11, e-mail: vpopov2010@yandex.ru.

Соловьева Ксения Сергеевна - студент, Иркутский государственный университет, 664011, г. Иркутск, ул. Сухэ-Батора, 5, e-mail: tarakam97@gmail.com.

\section{Для цитирования}

Лопатовская О. Г. Влияние сплошных рубок на лесорастительные свойства почв Братского района Иркутской области / О.Г. Лопатовская, Е.Н.Максимова, В. В. Попов, К. С. Соловьева // Известия Байкальского государственного университета. - 2018 . T. 28, № 1. - C. 159-165. - DOI: 10.17150/25002759.2018.28(1).159-165.

\section{Authors}

Olga G. Lopatovskaya - PhD in Biology, Associate Professor, Department of Soil Science and Land Resources Assessment, Irkutsk State University, 5 Sukhe-Bator St., 664011, Irkutsk, the Russian Federation, e-mail: lopatovs@gmail.com.

Evgeniya N. Maksimova - PhD in Biology, Associate Professor, Department of Natural Sciences, Irkutsk State University, 9 Sukhe-Bator St., 664011, Irkutsk, the Russian Federation, e-mail: evgen_max@list.ru.

Viktor V. Popov - PhD in Biology, Director of the Institute for Natural Resource Management and Conservation of Biodiversity, Baikal State University, 11 Lenin St., 664003, Irkutsk, the Russian Federation, e-mail: vpopov2010@yandex.ru.

Kseniya S. Solovyova - Student, Irkutsk State University, 5 Sukhe-Bator St., 664011, Irkutsk, the Russian Federation, e-mail: lopatovs@gmail.com.

\section{For citation}

Lopatovskaya O. G., Maksimova E. N., Popov V. V., Solovyova K. S. The Influence of Clearcut Logging on the Forest Growth Properties of Soils of Bratsk District of Irkutsk Oblast. Izvestiya Baykal'skogo gosudarstvennogo universiteta $=$ Bulletin of Baikal State University, 2018, vol. 28, no. 1, pp. 159-165. DOI: 10.17150/2500-2759.2018.28(1).159-165. (In Russian). 